\title{
OPTIMALISASI PANGKALAN UTAMA TNI ANGKATAN LAUT I BELAWAN GUNA MENJAMIN KEAMANAN LAUT DI SELAT MALAKA
}

\author{
Monang S.H.S Malau 1), Hari Subagyo ${ }^{2)}$, Hendro Yusworo ${ }^{3)}$ \\ Markas Besar Angkatan Laut Sekolah Staf Dan Komando \\ e-mail: malaumonang171@gmail.com ${ }^{1,2,3}$
}

\begin{abstract}
The purpose of this research is to contribute ideas to leaders, as one of the alternative solutions in managing the base function according to the type of base so that it can function properly according to basic principles to support operations and training elements in the waters of the Malacca Strait. The problem found is that Sarpras is not optimal. 5R function support. Human resources have not met the DSP with suboptimal quality. The organization of tasks and procedures (Orgaspros) is not well organized. The Malacca Strait is the most important shipping lane in the world that forms a canal shipping lane between the Indian Ocean and the Pacific Ocean. As many as 50,000 ships pass through the Malacca Strait annually, transporting between one-fifth and a quarter of the world's sea trade. part of the SSAT plays a very important role in ensuring maritime security in the Malacca Strait. Lantamal I Belawan requires an organizational structure and an orderly division of tasks through a leadership pattern that is balanced between organizational interests and individual potential development of personnel.
\end{abstract}

\section{Keywords: Infrastructure, Human Resources, Marine Security}

\begin{abstract}
Abstrak
Tujuan dari penelitian ini untuk memberikan sumbangan pemikiran kepada pemimpin, sebagai salah satu upaya pemecahan alternatif dalam mengelola fungsi pangkalan sesuai tipe pangkalan sehingga dapat berfungsi dengan baik sesuai asasi guna mendukung operasi dan latihan unsur di perairan Selat Malaka.Permasalahan yang di temukan yaitu belum optimalnya Sarpras pendukung fungsi $5 R$. Sumber daya manusia belum memenuhi DSP dengan kualitas yang belum optimal.Organisasi tugas dan prosedur (Orgaspros) belum tertata dengan baik.Selat Malaka merupakan jalur pelayaran terpenting di dunia yang membentuk jalur pelayaran terusan antara Samudra Hindia dan Samudra Pasifik. Sebanyak 50.000 kapal melintasi Selat Malaka setiap tahunnya, mengangkut antara seperlima dan seperempat perdagangan laut dunia.Selat Malaka merupakan salah satu flash point di wilayah Indonesia dengan titik rawan ancaman dan wilayah vital serta daerah perbatasan yang paling mungkin berpotensi menimbulkan konflik, sehingga dukungan pangkalan yang merupakan bagian dari SSAT sangat berperan dalam menjamin keamanan laut di Selat Malaka.Lantamal I Belawan membutuhkan struktur organisasi dan tahapan pembagian tugas yang tertata melalui pola kepemimpinan yang seimbang antara kepentingan organisasi dan pengembangan potensi individu personel.
\end{abstract}

\section{Kata kunci: Sarana Prasarana, Sumber Daya Manusia, Keamanan Laut}

\section{PENDAHULUAN}

Tugas Tentara Nasional Indonesia Angkatan Laut (TNI AL) adalah melaksanakan tugas TNI matra laut di bidang pertahanan, menegakkan hukum dan menjaga keamanan di wilayah laut yuridiksi nasional, melaksanakan tugas diplomasi dalam rangka mendukung kebijakan politik luar negeri yang ditetapkan pemerintah, melaksanakan tugas TNI dalam 
pembangunan pengembangan kekuatan matra laut dan pemberdayaan wilayah pertahanan laut (Lembaga Sekretaris Negara RI, 2004). Selat Malaka merupakan salah satu jalur pelayaran terpenting di dunia, sama pentingnya seperti Terusan Suez atau Terusan Panama. Selat Malaka membentuk jalur pelayaran terusan antara Samudra Hindia dan Samudra Pasifik. Sebanyak 50.000 kapal melintasi Selat Malaka setiap tahunnya, mengangkut antara seperlima dan seperempat perdagangan laut dunia membuat Selat Malaka merupakan salah satu pusat lalu lintas pelayaran terpadat di dunia (Selat Malaka,2018). Penyelenggaraan tugas TNI AL di Selat Malaka melibatkan unsur KRI/KAL, pesawat udara (Pesud), pasukan pendarat (Pasrat) dan didukung oleh gelar pangkalan sebagai bagian integral dari Sistem Senjata Armada Terpadu (SSAT). Sebagai bagian dari SSAT, Pangkalan Utama TNI AL I (Lantamal I) Belawan menjalankan fungsi pangkalan dalam mendukung gelar kekuatan yang dilaksanakan TNI AL terhadap pelaksanaan operasi pengamanan di Selat Malaka dalam rangka menegakkan hukum di laut. Kondisi Lantamal I Belawan saat ini terkait dengan fungsi pangkalan dalam memberi dukungan kepada unsur yang sedang menjalankan gelar operasi di Selat Malaka masih belum ideal. Terbatasnya sarana dan prasarana (Sarpras) dalam mendukung fungsi 5R yaitu pemangkalan (Rebase), perbaikan (Repair), pembekalan (Replanishment) dan perawatan personel (Rest and Recreation), jumlah dan kemampuan personel belum memenuhi daftar susunan personel (DSP) serta organisasi tugas dan prosedur (Orgaspros) yang sering mengalami perubahan mengakibatkan sering terjadinya tumpang tindih pelaksanaan tugas antar satuan kerja (Satker). Dari Kondisi tersebut dibutuhkan upaya-upaya untuk meningkatkan modernisasi Sarpras pendukung fungsi $5 R$ sesuai dengan syarat klasifikasi pangkalan kelas $A$, penambahan jumlah personel yang mumpuni sebagai pengawak pangkalan sesuai dengan DSP yang telah ditetapkan serta penataan Orgaspros yang terstruktur dan efisien dalam menjalankan tugas pokok Lantamal I Belawan secara keseluruhan. Belum optimalnya fungsi pangkalan Lantamal I Belawan dalam mendukung gelar unsur yang beroperasi di Selat Malaka berdampak pada ketahanlamaan operasi dan kesiapan teknis unsur sehingga KRI yang melaksanakan operasi dan latihan tidak dapat secara optimal menjamin keamanan laut di Selat Malaka. Demikian juga dengan jumlah dan kualitas personel yang sangat terbatas melalui pelaksanaan tugas dan prosedur yang belum tertata, maka tidak akan tercapai standarisasi kemampuan yang dipersyaratkan dalam pelaksanaan tugas pokok Lantamal I Belawan guna menjamin keamanan Selat Malaka sehingga mengakibatkan terjadinya peningkatan ancaman Garwil dan Kamla di Selat Malaka dan dapat mengganggu stabilitas keamanan kawasan. Permasalahan tersebut diatas akan 
terpecahkan apabila dilaksanakan upaya yang bersifat komprehensif terhadap fungsi pangkalan Lantamal I Belawan dalam mendukung unsur yang melaksanakan operasi di Selat Malaka yaitu Markas Besar (Mabes) TNI AL perlu merumuskan kembali fungsi pembinaan personel (Binpers) dalam kegiatan dukungan fungsi pangkalan, modernisasi teknologi dan melengkapi Sarpras pangkalan serta membenahi Orgaspros secara terpusat sehingga terdapat keseragaman tugas gelar pangkalan di seluruh wilayah yurisdiksi nasional. Untuk mencapai ke arah tersebut, perlu kiranya dilaksanakan optimalisasi yang memuat kebijakan, strategi dan upaya-upaya untuk dapat lebih mengoptimalkan fungsi dukungan pangkalan Lantamal I Belawan. Apabila optimalisasi tersebut dapat terwujud, maka pengamanan wilayah perairan Selat Malaka guna mengatasi ancaman pelanggaran wilayah (Garwil) dan ancaman keamanan laut (Kamla) diharapkan akan tercapai dalam rangka mendukung tugas pokok TNI AL.

\section{METODE}

Metode penelitian menggunakan kualitatif dan kuantitatif, dengan menggunakan metode penelitian deduktif. Sedangkan pendekatan yang digunakan adalah penelitian lapangan dan studi kepustakaan ditunjang dengan pendekatan empiris berdasarkan pengalaman penugasan. Secara rinci, metode yang digunakan sebagai berikut : 1) landasan peraturan perundangan, kajian teori dan kajian pustaka digunakan metode content analysis yaitu pembahasan mendalam untuk memperoleh kajian tentang teori yang tepat untuk digunakan dalam menjelaskan dan menganalisis permasalahan yang sedang diteliti, 2) analisis kondisi saat ini digunakan penelitian dengan analisis kualitatif didukung data kuantitatif untuk menggambarkan atau mendeskripsikan data dengan menggunakan parameter serta hipotesis sebagai tolok ukurnya. Pengumpulan data dilakukan melalui penyebaran kuesioner dan wawancara untuk menguji hipotesis yang telah dibuat di lingkungan Lantamal I Belawan; 3) penyusunan strategi menggunakan analisis SWOT.

\section{HASIL DAN PEMBAHASAN}

Kekuatan unsur KRI yang dilengkapi dengan peralatan canggih dan modern, tidak akan berarti tanpa keberadaan pangkalan ideal dengan fasilitas yang mampu mendukung kebutuhan logistik operasi unsur. Hal ini sangat relevan apabila dilihat dari konstelasi geografis Indonesia yang sebagian besar wilayahnya merupakan lautan. Selain itu, posisi Lantamal I sebagai satu-satunya pangkalan yang berada di Selat Malaka banyak memberikan kontribusi 
dukungan bagi satuan operasi di wilayah perairan tersebut. Dalam memberikan dukungan tersebut ada beberapa hal yang harus diperhatikan, yaitu :

\section{Sarana dan prasarana dukungan fungsi $5 R$.}

Pelaksanaan fungsi dukungan yang ideal oleh Lantamal I sangat tergantung dari kemampuan dan kesiapan fasilitas yang dimiliki, fasilitas disini berupa fasilitas labuh (Rebase), fasilitas pemeliharaan dan perbaikan (Repair), fasilitas perbekalan (Replanishment) serta fasilitas perawatan personel (Rest and Recreation). Dukungan yang ideal dari Lantamal I akan berkontribusi pada pelaksanaan operasi yang dilaksanakan oleh satuan operasi. Hal ini menjadi penting mengingat luasnya wilayah laut dan banyaknya akses maritim yang terdapat di wilayah perairan Selat Malaka, sehingga mendorong perlunya jaminan terhadap keamanan perairan Selat Malaka dengan tidak mengabaikan berbagai kepentingan internasional. Jaminan keamanan perairan Selat Malaka mempunyai korelasi yang kuat terhadap kesiapan $\mathrm{KRI}$ sebagai satuan pelaksana operasi keamanan laut dan pangkalan sebagai pendukungnya.

\section{Jumlah dan Kualitas Sumber daya manusia (SDM).}

Menurut Ken Booth, Angkatan Laut sebagai bagian utama dari kekuatan laut secara universal mempunyai peran penting yaitu peran militer, polisionil dan diplomasi (Ken Booth,1977). Peran polisionil TNI AL pada hakekatnya adalah penggunaan kekuatan secara optimal untuk menjamin keamanan wilayah laut yurisdiksi nasional. Jumlah dan kualitas personel pengawak pangkalan Lantamal I Belawan merupakan hal yang mutlak harus diperhitungkan berdasarkan analisa skenario ancaman di wilayah perairan Selat Malaka, bahwa ancaman keamanan adalah ancaman faktual sedangkan ancaman agresi militer kekuatan bersenjata masih merupakan ancaman potensial namun sewaktu-waktu dapat berkembang menjadi ancaman faktual. Berdasarakan analisa skenario ancaman tersebut maka idealnya jumlah dan kualitas personel pengawak Lantamal I Belawan dapat di sesuaikan dengan analisa ancaman faktual.

\section{Organisasi tugas dan prosedur (Orgaspros).}

Orgaspros di lingkungan TNI AL merupakan tahapan prosedur sistem pembagian tugas tiap-tiap satuan yang terorganisir, disesuaikan dengan ketentuan organisasi yang divalidasi melalui ketetapan pimpinan dan peraturan pemerintah. Orgaspros Lantamal I 
Belawan yang optimal dengan tahapan pelaksanaan tugas yang tertata dengan baik akan memberikan kontribusi positif terhadap terjaminnya keamanan laut di Selat Malaka. Dengan optimalnya pengorganisasian tugas dan prosedur di Lantamal I Belawan akan memperjelas tahapan pelaksanaan tugas antar Satker sesuai fungsi dan kemampuannya, sehingga tidak terjadi tumpang tindih pelaksanaan tugas personel pengawak Lantamal I belawan dalam melaksanakan tugasnya. Perumusan kebijakan diperlukan sebagai pedoman dasar dalam menentukan strategi sebelum di implementasikan dalam upaya-upaya nyata. Perumusan kebijakan harus dapat menjadi solusi masalah dengan mempertimbangkan peluang dan kendala untuk mencapai sasaran sesuai dengan indikator keberhasilan yang secara ringkas disajikan pada tabel 1.

\section{Tabel 1.Rumusan optimalisasi dukungan pangkalan Belawan}

\begin{tabular}{|c|c|}
\hline Masalah & $\begin{array}{l}\text { Dukungan Pangkalan TNI Angkatan Laut I Belawan belum optimal pada } \\
\text { pelaksanaan dukungan administrasi dan logistik bagi unsur KRI yang beroperasi } \\
\text { di wilayahnya guna menjamin keamanan laut di Selat Malaka dalam rangka } \\
\text { mendukung tugas TNI Angkatan Laut. }\end{array}$ \\
\hline $\begin{array}{l}\text { Pokok } \\
\text { Persoalan }\end{array}$ & $\begin{array}{l}\text { a. Belum optimalnya sarana dan prasarana pendukung (fungsi } 5 \mathrm{R} \text { ) di Lantamal I } \\
\text { Belawan sebagai pangkalan tipe A. } \\
\text { b. Sumber daya manusia belum optimal yang secara kuantitas belum memenuhi } \\
\text { Daftar Susunan Personel (DSP) sehingga mempengaruhi kinerja secara kualitas. } \\
\text { c. Belum optimalnya penataan Organisasi tugas dan prosedur (Orgaspros) } \\
\text { sebagai acuan tahapan pelaksanaan tugas. }\end{array}$ \\
\hline Peluang & $\begin{array}{l}\text { a. Letak strategis Lantamal I Belawan dengan wilayah kerja meliputi tiga propinsi } \\
\text { sebagai satu-satunya pangkalan tipe A di Selat Malaka. } \\
\text { b. Komandan Lantamal I Belawan merupakan salah satu FKPD Propinsi Sumatera } \\
\text { Utara memiliki nilai tawar tinggi dalam peran menegakkan kedaulatan dan } \\
\text { menjaga keamanan laut di wilayah kerjanya. } \\
\text { c. Kordinasi dengan instansi lain berjalan sangat baik. } \\
\text { d. UU RI No.16 Th. } 2012 \text { tentang Industri pertahanan memprioritaskan Industri } \\
\text { nasional untuk memenuhi kepentingan strategis Hankamneg. } \\
\text { e. Bantuan administrasi dan logistik di wilayah Propinsi Sumatera Utara untuk } \\
\text { kebutuhan operasi dapat diperoleh dengan mudah. } \\
\text { f. Injasmar di sekitar Mako Lantamal I Belawan mempunyai efek langsung } \\
\text { terhadap kemampuan pangkalan secara ekonomis dan praktis. }\end{array}$ \\
\hline Kendala & $\begin{array}{l}\text { a. Kondisi Sarpras pendukung pangkalan masih berada di bawah standar } \\
\text { profesionalisme merupakan aset ketinggalan teknologi. } \\
\text { b. Secara kuantitas personel Lantamal I Belawan belum memenuhi DSP sehingga } \\
\text { mempengaruhi kinerja secara kualitas. } \\
\text { c. Orgaspros di Lantamal I Belawan sering mengalami perubahan dan minimnya } \\
\text { pemahaman tingkat pimpinan mengenai prosedur pembagian tugas serta } \\
\text { kemampuan beberapa Satker yang sangat terbatas. } \\
\text { d. Keterbatasan kemampuan pangkalan dan SDM pengawaknya dihadapkan } \\
\text { dengan kekuatan pertahanan militer TNI AL yang terus mengikuti perkembangan } \\
\text { Iptek. } \\
\text { e. Seiring dengan perkembangan Alutsista yang beragam jenis dan tipenya, } \\
\text { harus diimbangi sistem pembinaan logistik yang modern. } \\
\text { f. Alokasi anggaran pertahanan yang minim membuat pencapaian kekuatan } \\
\text { pokok minimum (MEF) berjalan lamban. }\end{array}$ \\
\hline
\end{tabular}




\begin{tabular}{|c|c|}
\hline \multirow{3}{*}{$\begin{array}{l}\text { Indikator } \\
\text { Keberhasilan }\end{array}$} & $\begin{array}{l}\text { a. Optimalisasi dukungan pangkalan Lantamal I Belawan } \\
\text { 1) Terpenuhinya sarana dan prasarana pendukung fungsi } 5 \mathrm{R} \text { pangkalan } \\
\text { kelas A sesuai dengan Keputusan Kepala Staf Angkatan Laut Nomor } \\
\text { Kep/1771/XII/2013 tentang buku petunjuk administrasi standarisasi } \\
\text { pangkalan TNI Angkatan Laut } \\
\text { 2) Terpenuhinya kebutuhan personel sesuai daftar susunan personel } \\
\text { (DSP) yang telah ditetapkan dan proses pembinaan personel (Binpers) } \\
\text { yang optimal. } \\
\text { 3) Orgaspros yang dikonsep secara top down dari pimpinan tingkat } \\
\text { Mabesal dengan memperhatikan dinamika perubahan DSP dan } \\
\text { mempertimbangkan kemampuan Satker tingkat Lantamal serta proses } \\
\text { pembagian tugas dari pimpinan tingkat Lantamal dengan memperhatikan } \\
\text { tahapan secara hirarkis sesuai porsi kemampuan Satker melalui pola } \\
\text { kepemimpinan human relation. }\end{array}$ \\
\hline & $\begin{array}{l}\text { b. Terjaminnya keamanan laut di Selat Malaka (Peraturan Kasal,2009) } \\
\text { 1) Tegaknya hukum di laut. } \\
\text { 2) Terlindunginya sumber daya dan kekayaan laut nasional. } \\
\text { 3) Terpeliharanya keamanan dan ketertiban di laut. }\end{array}$ \\
\hline & $\begin{array}{l}\text { C. Tugas pokok TNI AL (Lembaga Sekretaris Negara RI, 2004) } \\
\text { 1) Terlaksananya tugas TNI matra laut di bidang pertahanan. } \\
\text { 2) Tegaknya hukum dan terjaganya keamanan di wilayah laut yuridiksi } \\
\text { nasional } \\
\text { 3) Terlaksananya tugas diplomasi dalam rangka mendukung kebijakan } \\
\text { politik luar negeri yang ditetapkan pemerintah. } \\
\text { 4) Terlaksananya tugas TNI dalam pembangunan pengembangan } \\
\text { kekuatan matra laut dan pemberdayaan wilayah pertahanan laut }\end{array}$ \\
\hline
\end{tabular}

Sumber. Diolah dari berbagai sumber

\section{Kebijakan.}

Kebijakan optimalisasi dukungan pangkalan Lantamal I belawan diarahkan untuk dukungan unsur KRI yang beroperasi dalam menjaga stabilitas keamanan laut di Selat Malaka berdasarkan pertimbangan, hasil analisis dan pembahasan serta berbagai faktor yang mempengaruhi terkait dengan adanya peluang dan kendala. Maka kebijakan yang perlu diambil agar pelaksanaan dukungan pangkalan Lantamal I Belawan dapat terlaksana dengan efektif dan efisien adalah: "Terwujudnya dukungan pangkalan Lantamal I Belawan melalui peningkatan sarana dan prasarana pendukung fungsi $5 R$, peningkatan jumlah dan kualitas SDM serta penataan Orgaspros secara terpusat yang dilaksanakan dengan pola kepemimpinan human relation guna menjamin keamanan laut di Selat Malaka dalam rangka mendukung tugas TNI AL". Untuk mewujudkan kebijakan tersebut, maka diperlukan langkahlangkah nyata berupa beberapa strategi dan upaya-upaya yang harus dilaksanakan oleh berbagai pihak khususnya yang berhubungan langsung dengan dukungan pangkalan agar dapat memecahkan masalah dan pokok persoalan yang dihadapi sehingga kondisi yang diharapkan dapat terwujud. 


\section{Strategi.}

Kebijakan yang telah ditetapkan, perlu dijabarkan ke dalam strategi yang tepat, sehingga dapat dijadikan acuan dalam menentukan upaya yang akan dilakukan untuk mencapai suatu tujuan. Metode analisis yang digunakan dalam menentukan strategi adalah menggunakan metode analisis SWOT yaitu analisis yang didasarkan pada logika untuk memaksimalkan kekuatan (Strenghts) dan peluang (Opportunities), namun secara bersamaan dapat meminimalkan kelemahan (Weakness) dan ancaman (Threats) (Fredy,2015). Adapun langkah-langkah yang digunakan, adalah sebagai berikut: 1) menentukan faktor kekuatan dan kelemahan sebagai faktor internal yang diambil dari kondisi saat ini terkait dengan dukungan pangkalan Lantamal I Belawan (Internal Factors Analysis Summary/IFAS); 2) menentukan faktor peluang dan ancaman sebagai faktor eksternal yang meliputi peluang dan ancaman diambil dari pembahasan tentang peluang dan kendala pada faktor yang mempengaruhi (External Factors Analysis Summary(EFAS), 3) langkah berikutnya adalah membuat pembobotan terhadap faktor internal dan eksternal. Bobot nilai serta penentuan rating didapatkan dari pendapat 20 (dua puluh) orang Pamen yang berdinas di Lantamal I Belawan. Dalam survei itu, responden akan memberikan pendapat tentang pentingnya kondisi relatif pada masing-masing faktor SWOT. Hasilnya dari survei tersebut diringkas dalam tabel pembobotan faktor SWOT. Penentuan rating juga didasarkan pada jawaban responden dan dimulai dari sangat setuju sampai dengan sangat tidak setuju, dan dari besar sampai dengan yang terkecil.

\section{Tabel 2. Pembobotan faktor internal}

\begin{tabular}{|c|c|c|c|c|c|c|c|c|}
\hline \multirow{3}{*}{ No } & \multirow{3}{*}{$\begin{array}{l}\text { Internal } \\
\text { Factors }\end{array}$} & \multicolumn{7}{|c|}{ Nilai Bobot } \\
\hline & & $\begin{array}{l}\text { Neg } \\
\text { Sig }\end{array}$ & $\begin{array}{l}\text { Neg } \\
\text { Tdk } \\
\text { Sig }\end{array}$ & $\begin{array}{l}\text { Pos } \\
\text { Tdk } \\
\text { Sig }\end{array}$ & $\begin{array}{l}\text { Pos } \\
\text { Sig }\end{array}$ & $\mathrm{Jml}$ & Bobot & $\begin{array}{l}\text { Norm } \\
\text { Bobot }\end{array}$ \\
\hline & & 4 & 2 & 2 & 4 & & & \\
\hline 1. & $\begin{array}{l}\quad \text { Kekuatan (Strength) } \\
\text { Letak strategis Lantamal I } \\
\text { Belawan berada di Kota } \\
\text { Medan Propinsi Sumut }\end{array}$ & - & - & 6 & 14 & 20 & 68 & 0,121 \\
\hline 2. & $\begin{array}{l}\text { Komandan Lantamal I } \\
\text { Belawan adalah anggota } \\
\text { FKPD Sumatera Utara }\end{array}$ & - & - & 4 & 16 & 20 & 76 & 0,136 \\
\hline 3. & $\begin{array}{l}\text { Kordinasi dengan instansi } \\
\text { lain berjalan sangat baik }\end{array}$ & - & - & 6 & 14 & 20 & 68 & 0,121 \\
\hline
\end{tabular}




\begin{tabular}{|c|l|c|c|c|c|c|c|c|}
\hline 1. & $\begin{array}{l}\text { Kelemahan (Weakness) } \\
\text { Sarpras pangkalan } \\
\text { Lantamal I Belawan } \\
\text { dibawah standar } \\
\text { profesionalisme dan } \\
\text { ketinggalan teknologi }\end{array}$ & 18 & 2 & - & - & 20 & 76 & 0,136 \\
\hline 2. & $\begin{array}{l}\text { Jumlah dan kemampuan } \\
\text { personel Lantamal I Belawan } \\
\text { sangat terbatas }\end{array}$ & 16 & 4 & - & - & 20 & 76 & 0,136 \\
\hline 3. & $\begin{array}{l}\text { Tumpang tindih pelaksanaan } \\
\text { tugas antar Satker akibat } \\
\text { Orgaspros Lantamal I } \\
\text { Belawan sering mengalami } \\
\text { perubahan }\end{array}$ & 14 & 6 & - & - & 20 & 68 & 0,121 \\
\hline
\end{tabular}

Sumber. Diolah dari berbagai sumber

\section{Tabel 3. Pembobotan faktor eksternal}

\begin{tabular}{|c|c|c|c|c|c|c|c|c|}
\hline \multirow{3}{*}{ No } & \multirow{3}{*}{$\begin{array}{l}\text { External } \\
\text { Factors }\end{array}$} & \multicolumn{7}{|c|}{ Nilai Bobot } \\
\hline & & $\begin{array}{c}\mathrm{Neg} \\
\mathrm{Sig}\end{array}$ & $\begin{array}{l}\text { Neg } \\
\text { Tdk } \\
\text { Sig }\end{array}$ & $\begin{array}{l}\text { Pos } \\
\text { Tdk } \\
\text { Sig }\end{array}$ & $\begin{array}{l}\text { Pos } \\
\text { Sig }\end{array}$ & \multirow[t]{2}{*}{$\mathrm{Jml}$} & \multirow[t]{2}{*}{ Bobot } & \multirow[t]{2}{*}{$\begin{array}{l}\text { Norm } \\
\text { Bobot }\end{array}$} \\
\hline & & 4 & 2 & 2 & 4 & & & \\
\hline 1. & $\begin{array}{l}\text { Peluang (Opportunity) } \\
\text { Bantuan administrasi dan } \\
\text { logistik diperoleh dengan } \\
\text { mudah di Propinsi Sumut } \\
\text { dengan potensi SDM tinggi. }\end{array}$ & - & - & 6 & 14 & 20 & 68 & 0,126 \\
\hline 2. & $\begin{array}{l}\text { MEF TNI AL tahap II dengan } \\
\text { rencana pembangunan dan } \\
\text { pengembangan organisasi. }\end{array}$ & - & - & 4 & 16 & 20 & 76 & 0,141 \\
\hline 3. & $\begin{array}{l}\text { Injasmar di sekitar Mako } \\
\text { Lantamal I Belawan adalah } \\
\text { komponen vital dari } \\
\text { kemampuan pertahanan. }\end{array}$ & - & - & 6 & 14 & 20 & 68 & 0,126 \\
\hline 1. & $\begin{array}{l}\quad \text { Ancaman (Threats) } \\
\text { Perkembangan modernisasi } \\
\text { Alutsista menuntut } \\
\text { kemampuan dukungan } \\
\text { pangkalan }\end{array}$ & 12 & 8 & - & - & 20 & 64 & 0,118 \\
\hline 2. & $\begin{array}{l}\text { Kekayan SDA Sumatera } \\
\text { Utara sangat melimpah } \\
\text { namun masih belum dikelola } \\
\text { dengan baik. }\end{array}$ & 14 & 6 & - & - & 20 & 68 & 0,126 \\
\hline 3. & $\begin{array}{l}\text { Anggaran pertahanan } \\
\text { pemerintah yang terbatas }\end{array}$ & 14 & 6 & - & - & 20 & 68 & 0,126 \\
\hline & & AH & & & & & 540 & 1 \\
\hline
\end{tabular}

Sumber. Diolah dari berbagai sumber

Proses selanjutnya adalah menentukan nilai rating dengan melakukan perhitungan seperti pada tabel 4 . 
Tabel 4. Penentuan Rating

\begin{tabular}{|c|c|c|c|c|c|c|c|c|}
\hline \multirow{3}{*}{ No } & \multirow{3}{*}{$\begin{array}{l}\text { Internal } \\
\text { Factors }\end{array}$} & \multicolumn{7}{|c|}{ Nilai Rating } \\
\hline & & STS & TS & S & SS & \multirow{2}{*}{ Jml } & \multirow{2}{*}{ Skor } & \multirow{2}{*}{ Rating } \\
\hline & & 1 & 2 & 3 & 4 & & & \\
\hline 1. & $\begin{array}{l}\text { Kekuatan (Strength) } \\
\text { Letak strategis Lantamal I } \\
\text { Belawan berada di Kota Medan } \\
\text { Propinsi Sumut }\end{array}$ & - & 3 & 6 & 11 & 20 & 68 & 3,4 \\
\hline 2. & $\begin{array}{l}\text { Komandan Lantamal I Belawan } \\
\text { adalah anggota FKPD } \\
\text { Sumatera Utara }\end{array}$ & - & - & 7 & 13 & 20 & 73 & 3,65 \\
\hline 3. & $\begin{array}{l}\text { Kordinasi dengan instansi lain } \\
\text { berjalan sangat baik }\end{array}$ & - & - & 9 & 11 & 20 & 71 & 3,55 \\
\hline 1. & $\begin{array}{l}\text { Kelemahan (Weakness) } \\
\text { Sarpras pangkalan Lantamal I } \\
\text { Belawan dibawah standar } \\
\text { profesionalisme dan ketinggalan } \\
\text { teknologi }\end{array}$ & - & 2 & 3 & 15 & 20 & 75 & 3,75 \\
\hline 2. & $\begin{array}{l}\text { Jumlah dan kemampuan } \\
\text { personel Lantamal I Belawan } \\
\text { sangat terbatas }\end{array}$ & - & 2 & 7 & 11 & 20 & 71 & 3,55 \\
\hline 3. & $\begin{array}{l}\text { Tumpang tindih pelaksanaan } \\
\text { tugas antar Satker akibat } \\
\text { Orgaspros Lantamal I Belawan } \\
\text { sering mengalami perubahan }\end{array}$ & - & 3 & 10 & 7 & 20 & 68 & 3,2 \\
\hline \multirow{3}{*}{\multicolumn{2}{|c|}{$\begin{array}{l}\text { External } \\
\text { Factors }\end{array}$}} & \multicolumn{7}{|c|}{ Nilai Rating } \\
\hline & & STS & TS & s & SS & \multirow{2}{*}{ Jml } & \multirow{2}{*}{ Skor } & \multirow{2}{*}{ Rating } \\
\hline & & 1 & 2 & 3 & 4 & & & \\
\hline 1. & $\begin{array}{l}\text { Peluang (Opportunity) } \\
\text { Bantuan administrasi dan } \\
\text { logistik diperoleh dengan } \\
\text { mudah di Propinsi Sumut } \\
\text { dengan potensi SDM tinggi. }\end{array}$ & - & - & 6 & 14 & 20 & 74 & 3,7 \\
\hline 2. & $\begin{array}{l}\text { MEF TNI AL tahap II dengan } \\
\text { rencana pembangunan dan } \\
\text { pengembangan organisasi. }\end{array}$ & - & - & 9 & 11 & 20 & 71 & 3,55 \\
\hline 3. & $\begin{array}{l}\text { Injasmar di sekitar Mako } \\
\text { Lantamal I Belawan adalah } \\
\text { komponen vital dari } \\
\text { kemampuan pertahanan. }\end{array}$ & - & - & 13 & 7 & 20 & 67 & 3,35 \\
\hline 1. & $\begin{array}{l}\text { Ancaman (Threats) } \\
\text { Perkembangan modernisasi } \\
\text { Alutsista menuntut perubahan } \\
\text { pola dukungan logistik pangkalan }\end{array}$ & - & - & 11 & 9 & 20 & 69 & 3,45 \\
\hline 2. & $\begin{array}{l}\text { Kekayan SDA Sumatera Utara } \\
\text { sangat melimpah namun masih } \\
\text { belum dikelola dengan baik. }\end{array}$ & - & 4 & 9 & 7 & 20 & 63 & 3,15 \\
\hline 3. & $\begin{array}{l}\text { Anggaran pertahanan } \\
\text { pemerintah yang terbatas }\end{array}$ & - & - & 14 & 6 & 20 & 66 & 3,3 \\
\hline
\end{tabular}

Sumber. Diolah dari berbagai sumber 
Selanjutnya dilaksanakan penghitungan berdasarkan Internal Factor Analysis Summary (IFAS) dan External Factor Analysis Summary (EFAS) agar dapat ditemukan selisih angka yang menunjukan kuadran strategi.

Tabel 5. Matriks hasil IFAS dan EFAS

\begin{tabular}{|c|c|c|c|c|}
\hline \multicolumn{2}{|r|}{ Internal Factors Analysis Summary (IFAS) } & Bobot & Rating & $\begin{array}{l}\text { SKOR } \\
B \times R\end{array}$ \\
\hline \multicolumn{2}{|r|}{ Kekuatan (Strength) } & \multirow[b]{2}{*}{0,121} & \multirow[b]{2}{*}{3,4} & \multirow[b]{2}{*}{0,4114} \\
\hline S1 & Letak strategis Lantamal I Belawan di Kota Medan & & & \\
\hline $\mathrm{S} 2$ & Danlantamal I Belawan anggota FKPD Sumut & 0,136 & 3,65 & 0,4964 \\
\hline S3 & Kordinasi dengan instansi lain berjalan baik & 0,121 & 3,55 & 0,4296 \\
\hline \multicolumn{4}{|c|}{ JUMLAH } & 1,3374 \\
\hline \multicolumn{2}{|r|}{ Kelemahan (Weakness) } & & \multirow[b]{2}{*}{3,75} & \multirow[b]{2}{*}{0,51} \\
\hline W1 & Sarpras pangkalan ketinggalan teknologi & 0,136 & & \\
\hline W2 & Jumlah dan kemampuan personel sangat terbatas & 0,136 & 3,55 & 0,4828 \\
\hline W3 & Tumpang tindih pelaksanaan tugas antar Satker & 0,121 & 3,2 & 0,3872 \\
\hline \multicolumn{2}{|r|}{ JUMLAH } & 1 & Selisih & $\begin{array}{c}1,38 \\
-0,0426\end{array}$ \\
\hline & External Factors Analysis Summary (EFAS) & Bobot & Rating & $\begin{array}{c}\text { SKOR } \\
\text { B x R }\end{array}$ \\
\hline \multicolumn{2}{|r|}{ Peluang (Opportunity) } & \multirow[b]{2}{*}{0,126} & \multirow[b]{2}{*}{3,7} & \multirow[b]{2}{*}{0,4662} \\
\hline 01 & Bantuan Adminlog diperoleh dengan mudah. & & & \\
\hline $\mathrm{O} 2$ & MEF TNI AL tahap II. & 0,141 & 3,55 & 0,5006 \\
\hline $\mathrm{O3}$ & Injasmar di sekitar Mako Lantamal I Belawan. & 0,126 & 3,35 & 0,4221 \\
\hline \multicolumn{4}{|c|}{ JUMLAH } & 1,3889 \\
\hline \multicolumn{2}{|r|}{ Ancaman (Threats) } & & \multirow[b]{2}{*}{3,45} & \multirow[b]{2}{*}{0,4071} \\
\hline $\mathrm{T} 1$ & Perkembangan modernisasi Alutsista. & 0,118 & & \\
\hline T2 & Kekayan SDA belum dikelola dengan baik. & 0,126 & 3,15 & 0,3969 \\
\hline T3 & Anggaran pertahanan pemerintah yang terbatas. & 0,126 & 3,3 & 0,4158 \\
\hline \multicolumn{2}{|r|}{ JUMLAH } & 1 & Selisih & $\begin{array}{l}1,2198 \\
\mathbf{0 , 1 6 9 1} \\
\end{array}$ \\
\hline
\end{tabular}

Sumber. Diolah dari berbagai sumber

Selanjutnya untuk menentukan strategi terpilih pada kuadran W-O dari beberapa alternatif yang telah dirumuskan, maka dapat dirangking urutan strategi seperti ditunjukkan pada Tabel 6.

Tabel 6. Rumusan strategi

\begin{tabular}{|c|c|c|c|c|}
\hline $\begin{array}{c}\text { RUMUSAN } \\
\text { STRATEGI }\end{array}$ & HASIL W & HASIL O & JUMLAH & URUT \\
\hline W1-O1 & 0,51 & 0,4662 & 0,2378 & \\
\hline W1-O2 & 0,51 & 0,5006 & 0,2553 & $\mathbf{1}$ \\
\hline
\end{tabular}




\begin{tabular}{|l|l|l|l|l|}
\hline W1-O3 & 0,51 & 0,4221 & 0,2153 & \\
\hline \multicolumn{5}{|l|}{} \\
\hline W2-O1 & 0,4828 & 0,4662 & 0,2251 & \\
\hline W2-O2 & 0,4828 & 0,5006 & 0,2417 & $\mathbf{2}$ \\
\hline W2-O3 & 0,4828 & 0,4221 & 0,2038 & \\
\hline \multicolumn{7}{|l|}{} \\
\hline W3-O1 & 0,3872 & 0,4662 & 0,1805 & \\
\hline W3-O2 & 0,3872 & 0,5006 & 0,1938 & $\mathbf{3}$ \\
\hline W3-O3 & 0,3872 & 0,4221 & 0,1634 & \\
\hline
\end{tabular}

Sumber. Diolah dari berbagai sumber

Berdasarkan kebijakan dan perangkingan strategi pada Tabel 6 dapat diambil kesimpulan bahwa prioritas rumusan strategi kombinasi W-O yaitu memanfaatkan peluang 2 (O2) untuk mengatasi kelemahan secara berurutan mulai dari mengatasi kelemahan 1 (W1), kelemahan 2 (W2) dan kelemahan 3 (W3). Ketiga strategi tersebut dapat dirumuskan sebagai berikut:

Strategi 1. Mewujudkan dukungan pangkalan Lantamal I belawan yang optimal melalui peningkatan Sarpras pendukung fungsi $5 \mathrm{R}$ sebagai rencana strategis pembangunan MEF TNI AL tahap II.

Strategi 2. Mewujudkan dukungan pangkalan Lantamal I belawan yang optimal dengan meningkatkan jumlah personel sesuai DSP yang telah ditetapkan dan meningkatkan kualitas SDM melalui wadah transfer teknologi secara praktis mengikuti perkembangan Iptek sebagai rencana strategis pembangunan personel pada MEF TNI AL tahap II.

Strategi 3. Mewujudkan dukungan pangkalan Lantamal I belawan yang optimal melalui Orgaspros yang dikonsep secara top down sesuai porsi kemampuan Satker sebagai rencana strategis pengembangan dan validasi organisasi pada MEF TNI AL tahap II.

\section{Upaya.}

Berdasarkan kebijakan dan strategi yang telah dirumuskan pada bagian sebelumnya, maka hal tersebut dijabarkan dalam upaya-upaya yang harus dilakukan sebagai tindakan nyata dari siapa yang berbuat (subjek), terhadap apa (objek) dan dengan cara apa (metode) mengarah kepada sasaran mengoptimalkan kemampuan dukungan pangkalan Lantamal I Belawan guna menjamin keamanan laut di Selat Malaka dalam rangka mendukung tugas TNI AL. Adapun upaya-upaya dan kegiatan yang dilaksanakan untuk mewujudkan strategi yang telah ditetapkan tersebut adalah sebagai berikut :1) Implementasi strategi 1 Mewujudkan dukungan pangkalan Lantamal I belawan yang optimal melalui peningkatan Sarpras pendukung fungsi $5 \mathrm{R}$ sebagai rencana strategis pembangunan MEF TNI AL tahap II, adalah dengan melalui upaya-upaya : a). mabes TNI AL dalam hal ini Staf Perencanaan mempercepat 
dan memprioritaskan pembangunan pangkalan di wilayah strategis Selat Malaka sesuai standarisasi yang sudah ditetapkan guna memaksimalkan fungsi pangkalan bagi unsur yang beroperasi; b). mabes TNI AL dalam hal ini Staf Operasi berkordinasi dengan Pushidrosal guna melaksanakan pemeliharaan dan penambahan kedalaman laut di dermaga melalui pelaksanaan survei Hidrooseanografi secara periodik sehingga tidak terjadi pendangkalan di sekitar perairan dermaga Mako Lantamal I Belawan; c). mabes TNI AL dalam hal ini Disfaslanal membuat kebijakan dalam menganalisa dan rencana kelanjutan pembangunan fasilitas doking dan perbaikan slip way Fasharkan Belawan; d). mabes TNI AL dalam hal ini Staf Logistik membuat standarisasi prosedur tetap mengenai pelaksanaan, pengawasan dan evaluasi proses pembekalan bahan bakar yang diterima unsur KRI sehingga kualitas dan kuantitas bahan bakar dapat terjaga; e). mabes TNI AL dalam hal ini Disbekal membuat kebijakan perencanaan kebutuhan bekal pangkalan sebagai prioritas dengan memaksimalkan proses distribusinya sehingga penggunaan bekal pangkalan dapat berjalan tepat guna, tepat waktu dan tepat sasaran; f). mabes TNI AL dalam hal ini Disfaslanal membuat kebijakan prioritas perencanaan pembangunan dan menetapkan standarisasi pergudangan di pangkalan guna menjaga kualitas penyimpanan bekal kelas I sampai dengan $X ; g)$. mabes TNI AL dalam hal ini Disfaslanal menetapkan kebijakan perencanaan dan mengevaluasi kembali susunan tata ruang Mako Lantamal I Belawan dengan tetap memperhatikan fasilitas perawatan personel; h). koarmada 1 dalam hal ini Staf Logistik menetapkan kebijakan pada prioritas susunan program kerja tahunan untuk pembangunan pangkalan di wilayah strategis Selat Malaka sesuai standarisasi yang sudah ditetapkan guna memaksimalkan fungsi pangkalan bagi unsur yang beroperasi; i) koarmada 1 dalam hal ini Staf Logistik menetapkan kebijakan prioritas susunan program kerja tahunan untuk pembangunan Sarpras dan peralatan bengkel Fasharkan Belawan guna meningkatkan ketahanlamaan operasi dan kondisi teknis unsur yang beroperasi di perairan Selat Malaka; j) koarmada 1 menetapkan kebijakan dalam meningkatkan responsif terhadap kebutuhan logistik unsur KRI yang beroperasi di wilayah perairan Selat Malaka yang diusulkan oleh Lantamal I Belawan secara hirarkis dengan memperhatikan asas kecepatan, ketepatan, keamanan dan keselamatan pelaksanaannya; k) lantamal I Belawan memonitor dan mengevaluasi kondisi teknis Sarpras pendukung pangkalan dan mengajukan usulan pembangunan serta perbaikan secara hirarkis kepada Mabesal, 2) implementasi strategi 2 Mewujudkan dukungan pangkalan Lantamal I belawan yang optimal dengan meningkatkan jumlah personel sesuai DSP yang telah ditetapkan dan meningkatkan kualitas SDM melalui wadah transfer teknologi secara praktis 
mengikuti perkembangan Iptek sebagai rencana strategis pembangunan personel pada MEF TNI AL tahap II, dilakukan melalui upaya-upaya: a) mabes TNI AL dalam hal ini Staf Perencanaan mendorong kebijakan pemerintah pusat dalam hal peningkatan anggaran belanja pegawai dengan menetapkan pengadaan personel yang diprioritaskan sebagai pengawak pangkalan pada MEF TNI AL; b) mabes TNI AL dalam hal ini Staf Personel memvalidasi daftar susunan personel yang masih mengacu pada DSP tahun 2012 disesuaikan dengan susunan Orgaspros pangkalan terbaru 2018; c) mabes TNI AL dalam hal ini Disminpersal menerapkan kebijakan pembinaan personel pada fungsi penggunaan dengan melaksanakan pemerataan penempatan jabatan personel di seluruh gelar pangkalan yurisdiksi nasional sehingga konsentrasi jumlah personel tidak lagi terpusat di Pulau Jawa; d).

Mabes TNI AL dalam hal ini Disdikal berkordinasi dengan Kodiklatal guna memvalidasi kurikulum pendidikan disesuaikan dengan perkembangan Iptek terkini guna meningkatkan kemampuan prajurit TNI AL yang profesional mengikuti perkembangan modernisasi alat dan peralatan Alutsista; e) koarmada 1 dalam hal ini Staf Personel berkordinasi dengan Mabesal guna mendorong kebijakan agar Binpers pada fungsi penyediaan personel dilaksanakan berdasarkan persentase kebutuhan prajurit di setiap wilayah rekrutmen tidak lagi berdasarkan animo pendaftar; f) koarmada 1 dalam hal ini Staf Personel berkordinasi dengan Injasmar di seluruh wilayah kerjanya untuk bekerjasama dalam hal pelatihan secara teknis sebagai wadah transfer teknologi bagi prajurit; g). koarmada 1 dalam hal ini Kolatarmada 1 melaksanakan monitoring pada pelaksanaan pelatihan keterampilan pengawak pangkalan guna meningkatkan dan mejaga kemampuan personel Lantamal I Belawan dalam pelaksanaan tugas dukungan pangkalan di wilayah Selat Malaka; h) koarmada 1 dalam hal ini Kolatarmada 1 melaksanakan uji terampil latihan pangkalan serta memonitoring secara berkala sesuai standarisasi yang telah ditetapkan guna menjaga kemampuan prajurit pengawak pangkalan di wilayah kerjanya; i). lantamal I Belawan dalam hal ini Disminpers berkordinasi dengan Staf Personel Koarmada 1 dalam mengajukan kebutuhan personel secara berkala dan berjenjang guna menjaga keseimbangan komposisi personel yang ada; j). lantamal I Belawan dalam hal ini Staf Personel berkordinasi dengan Injasmar dan industri pertahanan setempat guna melaksanakan pembelajaran dan pelatihan personel dalam rangka peningkatan kemampuan melalui wadah transfer teknologi secara praktis mengikuti perkembangan Iptek terkini; k).Iantamal I Belawan dalam hal ini Staf Personel menetapkan kebijakan penjadwalan latihan dalam dinas (LDD) bagi prajurit dengan memonitor dan mengevaluasi pelaksanaannya guna menjaga kemampuan prajurit Lantamal I belawan, 3). 
implementasi strategi 3 Mewujudkan dukungan pangkalan Lantamal I belawan yang optimal melalui Orgaspros yang dikonsep secara top down sesuai porsi kemampuan Satker sebagai rencana strategis pengembangan dan validasi organisasi pada MEF TNI AL tahap II, adalah melalui upaya-upaya : a).mabes TNI AL dalam hal ini Staf Perencanaan menetapkan dan memvalidasi susunan Orgaspros secara terpusat sehingga terjadi keseragaman prosedur dan tahapan pelaksanaan tugas di seluruh gelar pangkalan sebagai wujud kebutuhan organisasi yang disesuaikan pada MEF TNI AL; b). mabes TNI AL dalam hal ini Staf Perencanaan berkordinasi dengan Staf Personel memvalidasi daftar susunan personel yang masih mengacu pada DSP tahun 2012 disesuaikan dengan susunan organisasi pangkalan terbaru 2018; c). mabes TNI AL dalam hal ini Disdikal berkordinasi dengan Kodiklatal dan Seskoal dalam menetapkan kurikulum pendidikan pengembangan bagi strata perwira mengenai pemahaman tentang tahapan Orgaspros yang menerapkan prinsip human relation pada tingkat manajerial sehingga terjadi keseimbangan antara kebutuhan organisasi dengan penggalian potensi personel pada saat pelaksanaan tugas di satuan; d). koarmada 1 melaksanakan monitoring mengenai kemampuan Satker yang ada di pangkalan dihadapkan dengan kelas pangkalan yang sudah distandarisasi sehingga tercapai pelaksanaan tugas pokok pangkalan secara keseluruhan sesuai yang diharapkan; e). koarmada 1 melaksanakan kordinasi dengan Mabesal untuk memvalidasi Fasharkan Belawan ditingkatkan dari Tipe B menjadi Tipe $A$ sebagai syarat Fasharkan yang berada di pangkalan Kelas $A ; f)$. koarmada 1 melaksanakan kordinasi dengan Mabesal untuk memvalidasi Rumkital Komang Makes ditingkatkan dari rumah sakit Kelas III menjadi Kelas II sebagai syarat standarisasi rumah sakit yang berada di pangkalan Kelas A; g). lantamal I Belawan dalam hal ini Staf Perencanaan melaksanakan monitoring pada pembinaan sistem prosedur organisasi dalam usaha menata dan membenahi pelaksanaan tahapan pembagian tugas antar Satker di Lantamal I Belawan; h). lantamal I Belawan dalam hal ini Staf Perencanaan berkordinasi secara berjenjang kepada Srena Koarmada 1 dan Srena Mabesal mengenai Orgaspros terbaru yang disesuaikan dengan perubahan struktur organisasi TNI AL dan DSP 2018. 


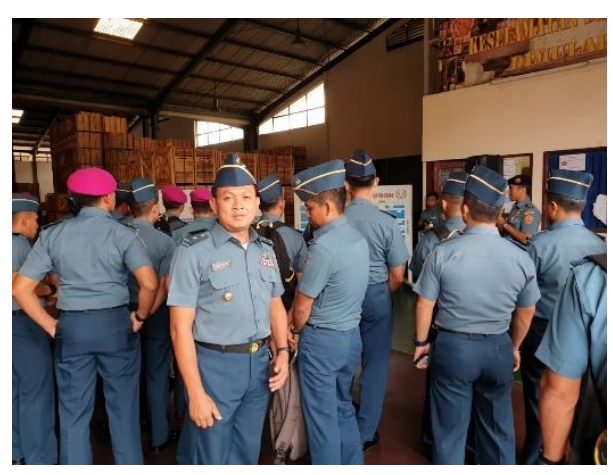

GAMBAR 1. FOTO KEGIATAN

\section{SIMPULAN}

Dalam Implementasi tugas TNI AL guna menegakkan hukum dan menjaga keamanan di wilayah laut Selat Malaka diperlukan adanya optimalisasi kemampuan pangkalan Lantamal I Belawan dapat ditarik kesimpulan bahwa Selat Malaka merupakan jalur pelayaran terpenting di dunia yang membentuk jalur pelayaran terusan antara Samudra Hindia dan Samudra Pasifik. Sebanyak 50.000 kapal melintasi Selat Malaka setiap tahunnya, mengangkut antara seperlima dan seperempat perdagangan laut dunia. Guna mengamankan daerah tersebut, TNI AL menggelar operasi pengamanan sepanjang tahun dengan melibatkan kekuatan SSAT dengan dukungan pangkalan kelas A di Selat Malaka adalah Lantamal I Belawan. Dukungan pangkalan tersebut meliputi fungsi $5 \mathrm{R}$ pangkalan melalui sarana dan prasarana fasilitas pemangkalan (rebase), pemeliharaan dan perbaikan (repair), pembekalan (Replanishment), peristirahatan personel (rest) dan rekreasi (recreation). Sarpras pangkalan tersebut berkontribusi pada tingkat ketahanlamaan dan kondisi teknis (operability) unsur KRI yang sedang melaksanakan operasi dan latihan. Agar stabilitas keamanan di kawasan tersebut dapat terjaga, ketahanlamaan operasi dan kondisi teknis unsur yang beroperasi di wilayah perairan Selat malaka harus ditingkatkan melalui dukungan fungsi 5R Lantamal I Belawan yang efektif dan efisien.

Selat Malaka merupakan salah satu flash point di wilayah Indonesia dengan titik rawan ancaman dan wilayah vital serta daerah perbatasan yang paling mungkin berpotensi menimbulkan konflik, sehingga dukungan pangkalan yang merupakan bagian dari SSAT sangat berperan dalam menjamin keamanan laut di Selat Malaka. Lantamal I Belawan memiliki peran penting dan strategis sebagai satu-satunya pangkalan kelas A di Selat Malaka dalam memberikan dukungan bagi unsur KRI yang sedang beroperasi di wilayah kerjanya. Peran strategis tersebut tidak lepas dari jumlah dan kemampuan personel pengawaknya yang merupakan elemen paling menentukan dalam keberhasilan pelaksanaan tugas pokok 
Lantamal I Belawan secara keseluruhan mengikuti perkembangan modernisasi Iptek.

Agar pola dukungan fungsi pangkalan bagi unsur KRI yang sedang melaksanakan operasi dan latihan di Selat Malaka berjalan dengan baik, Lantamal I Belawan membutuhkan struktur organisasi dan tahapan pembagian tugas yang tertata melalui pola kepemimpinan yang seimbang antara kepentingan organisasi dan pengembangan potensi individu personel sehingga kerjasama tim yang solid secara integral dapat terwujud dengan kinerja maksimal sebagai tolak ukur resultan keberhasilan tugasnya.

\section{DAFTAR PUSTAKA}

Fredy Rangkuti.2015. Analisis SWOT.Jakarta: Gramedia Pustaka Utama Ken Booth.1977. Navies and Foeign Policies. New York : Croom Helm Ltd

Lembaga Sekretaris Negara Republik Indonesia.2004.Undang-Undang Republik Indonesia Nomor 34 Tahun 2004 tanggal 16 Oktober 2004 tentang Tentara Nasional Indonesia. Jakarta: Setneg

Sekretariat Umum TNI AL.2009. Peraturan Kasal No. Perkasal/15/V/2009 tanggal 4 Mei 2009 tentang Prosedur tetap penanganan tindak pidana di laut oleh TNI AL. Jakarta : Mabesal Wikipedia Ensiklopedia Bebas.2018. Selat Malaka. https://id.wikipedia.org/wiki/Selat_Malaka. diakses pada tanggal 10 Maret 2018 pukul 10.05 WIB 